Article

\title{
Effects of Substrate Rotation Speed on Structure and Adhesion Properties of CrN/CrAlSiN Multilayer Coatings Prepared Using High-Power Impulse Magnetron Sputtering
}

\author{
Jian-Fu Tang ${ }^{1,2}$, Chun-Hong Huang ${ }^{2}$, Ching-Yen Lin ${ }^{2}$, Fu-Chi Yang ${ }^{1}$ and Chi-Lung Chang $1,2, * \mathbb{B}$ \\ 1 Center for Plasma and Thin Film Technologies, Ming Chi University of Technology, New Taipei City 24301, \\ Taiwan; chinglovejian@hotmail.com (J.-F.T.); fcyang@mail.mcut.edu.tw (F.-C.Y). \\ 2 Department of Materials Engineering, Ming Chi University of Technology, New Taipei City 24301, Taiwan; \\ m06188029@mail2.mcut.edu.tw (C.-H.H.); m07188012@mail2.mcut.edu.tw (C.-Y.L.) \\ * Correspondence: clchang@mail.mcut.edu.tw; Tel.: +886-2-29089899; Fax: +886-2-29084091
}

Received: 1 July 2020; Accepted: 27 July 2020; Published: 29 July 2020

\begin{abstract}
We investigated the effects of substrate rotation speed on the structural and mechanical properties of $\mathrm{CrN} / \mathrm{CrAlSiN}$ multilayer coatings produced using high-power impulse magnetron sputtering (HiPIMS) on silicon and high-speed steel (HSS) substrates. Structural analysis and characterization of the multilayer coatings were performed using an X-ray diffractometer (XRD), field emission scanning electron microscopy (FE-SEM), an electron probe microanalyzer (EPMA), and a transmission electron microscope (TEM). The thickness of the bi-layer film depended on the substrate rotation speed, as follows: 12 (1.5 rpm), 9.5 (2 rpm), 6 (3 rpm), 4 (4 rpm), and $3.2 \mathrm{~nm}(5 \mathrm{rpm})$. The results revealed that the hardness and coating-substrate adhesion strength increased inversely with the thickness of the bi-layer. TEM analysis revealed smaller columnar structures in thinner $\mathrm{CrN} / \mathrm{CrAlSiN}$ multilayer coatings. The highest results for hardness $(20.1 \mathrm{GPa})$, elastic modulus $(336 \mathrm{GPa})$, and adhesion strength $(77 \mathrm{~N})$ were obtained at a substrate rotation speed of $5 \mathrm{rpm}$. We also investigated the adhesion properties of the multilayer structures and formulated a hypothesis to explain adhesion strength.
\end{abstract}

Keywords: high-power impulse magnetron sputtering; rotation speed; multilayer; adhesion

\section{Introduction}

Coatings based on transition metal nitrides have proven highly effective in enhancing the performance of cutting tools, dies, and other mechanical components [1,2]. $\mathrm{CrN}$, in particular, has been used to extend the lifespan of components in a wide range of industrial applications due to its high hardness, excellent wear resistance, and good resistance to corrosion and oxidation [3-5]. Previous studies reported that doping $\mathrm{CrN}$ thin films with $\mathrm{Al}, \mathrm{Ti}, \mathrm{B}$, or $\mathrm{Si}$ can improve their mechanical properties. CrAlN coatings exhibit higher hardness than $\mathrm{CrN}$ coatings as well as superior thermal stability and a lower coefficient of friction [6-9]. Alloying $\mathrm{Al}$ to $\mathrm{CrN}$ was initially intended to enhance resistance to oxidation; however, ternary $\mathrm{AlCrN}$ films also exhibit excellent hardness and thermal stability due to the B1 structure of the metastable $\mathrm{Al}_{x} \mathrm{Cr}_{1-x} \mathrm{~N}$ solid solution and nanoscale-sized domains [10]. Zhang [11] and Chang et al. [12] reported that the hardness of CrAlSiN coatings exceeds that of $\mathrm{CrAlN}$ due to nanograins embedded within the amorphous $\mathrm{SiN}_{x}$ matrix, resulting in a smaller crystalline grain size.

Enhancing the hardness of thin films improved their mechanical properties; however, it can also lead to problems with adhesion. The adhesion of coatings to substrates is a key criterion in assessing the 
performance of tools in many industrial applications. Many methods have been developed to improve the adhesion of Cr-based coatings, including Ar plasma cleaning [13], metal ion bombardment [14], and the deposition of metal films $[15,16]$. Ar plasma cleaning removes surface contaminants and oxide layers prior to coating. High-energy metal ion bombardment creates a metal implantation zone, which promotes the formation of bonds between the substrate and coating. The application of a thin metal film (5-15 nm) was also used to improve adhesion [17]. In recent years, high-power impulse magnetron sputtering (HiPIMS) has been used to pre-treat substrate surfaces in metal/argon plasma prior to coating due to its high plasma density exceeding $10^{18} \mathrm{~m}^{-3}$, which allows for the ionization of a large fraction of the sputtered material [18]. Ehiasarian et al. [14] reported on microstructural changes at the interface between metallic interlayers and steel surfaces following bombardment with $\mathrm{Cr}$ and $\mathrm{Nb}$ ions via HiPIMS.

HiPIMS features low process temperatures to create films of high quality (high density and low surface roughness), which are far superior to those produced using conventional physical vapor deposition (PVD) processes $[19,20]$. Cathode arc evaporation (CAE) technology uses high-density plasma to increase the density of films; however, the formation of particles during the process undermines their mechanical properties and increases surface roughness. DC magnetron sputtering (DCMS) produces coatings with low surface roughness; however the low plasma density results in low-density films with poor mechanical properties [21-23]. Samuelsson et al. [24] reported that HiPIMS outperforms DCMS in terms of coating density. Paulitsch et al. [25] compared the hardness of films deposited using HiPIMS and DCMS as follows: CrN (23 vs. $15 \mathrm{GPa}$ ) and TiN (35 vs. $15 \mathrm{GPa}$ ).

Industrial PVD deposition systems rotate the substrate while depositing a homogeneous coating across the entire surface. These systems also allow for the mounting of multiple targets within the chamber to produce multilayer coatings with a variable modulation period simply by adjusting the rotation speed. Coatings with multilayered structures have proven highly effective in terms of wear resistance, anti-corrosion characteristics, fatigue life [26], and reduced crack propagation [27]. The application of multiple layers creates a path to deflect cracks and thereby prevent full delamination of the coating. Multilayer systems such as AlN/CrN [28], CrAlN/CrN [29], and TiAlSiN/CrN [30] have been studied extensively; however, coatings based on $\mathrm{CrN}$ and $\mathrm{CrAISiN}$ [31,32] have largely been overlooked. Researchers reported that multilayer coatings with a smaller modulated period $(\Lambda)$ value provide superior adhesion and corrosion resistance due to the chemical modulation period, the thickness ratio of individual layers, and the dense microstructure [33]. Martínez et al. [34] reported that the adhesion strength of $\mathrm{CrN} / \mathrm{Cr}$ multilayers increased inversely with the thickness of the modulation period. It appears that $\Lambda$ is a crucial parameter in the optimization of multilayer films.

In this work, CrN/CrAlSiN multilayer films were fabricated via HiPIMS with a focus on microstructure, modulation period, mechanical properties, and adhesion strength as a function of substrate rotation speed.

\section{Experiment Details}

The HiPIMS system used in this study was detailed in a previous study [35]. CrN/CrAlSiN multilayer coatings were deposited on 100-oriented silicon (Si) and high-speed steel (HSS: M2, $25 \mathrm{~mm}$ in diameter and $10 \mathrm{~mm}$ in thickness) substrates. Figure 1 presents a schematic illustration and TEM images showing the structure of the coatings. $\mathrm{Cr}$ and dual $\mathrm{Cr}_{30} \mathrm{Al}_{60} \mathrm{Si}_{10}$ targets $\left(45.3 \times 17 \mathrm{~cm}^{2}\right)$ were connected to a pulsed power supply (SPIK 3000A dual, MELEC GmbH, Baden-Baden, Germany) in bipolar output mode with the HiPIMS power maintained at $5 \mathrm{~kW}$. Deposition parameters are listed in Table 1 . The temperature of the chamber was kept below $85^{\circ} \mathrm{C}$ throughout the deposition process (i.e., no additional heating was applied). All substrates were cleaned in an ultrasonic cleaning bath with acetone and ethanol solution for $15 \mathrm{~min}$, and dried with pure nitrogen. Prior to deposition, the chamber was evacuated to below $6.6 \times 10^{-4} \mathrm{~Pa}$. Plasma etching was performed via Ar glow discharge (DC bias of $-1000 \mathrm{~V}$ ) under pressure of $0.5 \mathrm{~Pa}$. Ion bombardment was then conducted via HiPIMS for a period of $15 \mathrm{~min}$, during which the DC bias was gradually reduced in intervals of $5 \mathrm{~min}$ from -1000 to 
$-800,-600,-400$, and $-200 \mathrm{~V}$. During interlayer deposition, the Ar flow rate was reduced to $50 \mathrm{sccm}$ and maintained at that level during subsequent deposition. The initial power applied to the dual $\mathrm{Cr}$ targets was $5 \mathrm{~kW}$ (bipolar output mode). An interlayer of pure $\mathrm{Cr}$ was then deposited under DC bias of $-120 \mathrm{~V}$ over a period of $10 \mathrm{~min}$ under a working pressure of $0.5 \mathrm{~Pa}$. A $\mathrm{CrN}$ interlayer was then deposited by introducing $\mathrm{N}_{2}$ gas at a flow rate of $9 \mathrm{sccm}$ and working pressure of $0.5 \mathrm{~Pa}$ under a DC bias of $-60 \mathrm{~V}$ for $30 \mathrm{~min}$. A CrN/CrAlSiN transfer interlayer was created by increasing the $\mathrm{N}_{2} / \mathrm{Ar}$ flow ratio from $18 \%$ to $48 \%$ during deposition under DC bias of $-60 \mathrm{~V}$. The $\mathrm{CrN} / \mathrm{CrAlSiN}$ top layer was created by increasing the $\mathrm{N}_{2} /$ Ar flow ratio to $48 \%$, while simultaneously reducing the bias voltage from -60 to $-45 \mathrm{~V}$. With the working pressure maintained at $0.5 \mathrm{~Pa}$ for a period of $60 \mathrm{~min}$, the rotation rate of the substrate was varied (1.5-5 rpm) to create $\mathrm{CrN} / \mathrm{CrAlSiN}$ multilayers (top layer) with various modulation periods.

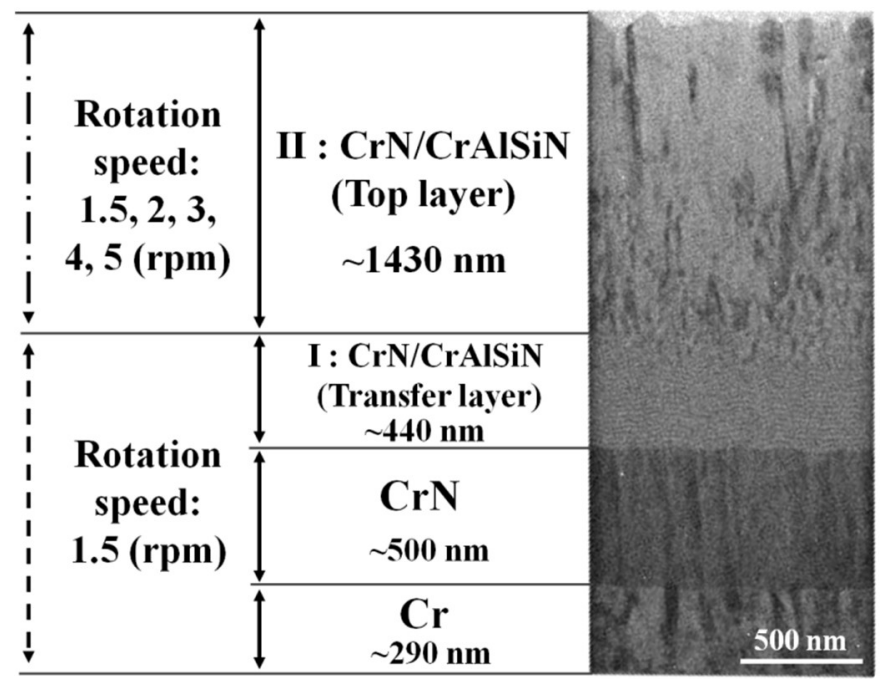

Figure 1. Schematic illustration and TEM image showing the coating structure.

Table 1. Experiment parameters used in HiPIMS deposition of $\mathrm{CrN} / \mathrm{CrAlSiN}$ multilayer coatings.

\begin{tabular}{cc}
\hline Parameter & Value \\
\hline Target Materials (99.9 at.\%) & $\mathrm{Cr}_{,} \mathrm{Cr}_{60} \mathrm{Al}_{30} \mathrm{Si}_{10}$ \\
Target-Substrate Distance (mm) & 90 \\
Working Pressure (Pa) & 0.5 \\
$\mathrm{~N}_{2}$ /Ar Flow Ratio (\%) & 48 \\
Multilayer Depositing Time (min) & 60 \\
Duty Cycle (\%) & 3 \\
Pulse Frequency (Hz) & 200 \\
Pulse On-Time/Off-Time ( $\mu \mathrm{s})$ & $150 / 4850$ \\
DC Bias Voltage (V) & -45 \\
Substrate Rotation Rate (rpm) & $1.5,2,3,4,5$ \\
\hline
\end{tabular}

Field emission scanning electron microscopy (FE-SEM, S8000, Hitachi, Tokyo, Japan) was used to characterize the surface and cross-sectional morphology of the coatings on Si wafers. Selected samples underwent subsequent analysis using a transmission electron microscope (TEM, JEOL, JEM-ARM200FTH, Tokyo, Japan), including selected area electron diffraction (SAED). Table 2 lists the thickness of bi-layer $\mathrm{CrN} / \mathrm{CrAlSiN}$ multilayer films fabricated using various substrate rotation speeds, with the thickness measurements obtained from TEM images. An X-ray diffractometer (XRD, PANalytical, X'pert MRD, Almelo, The Netherlands) with $\mathrm{Cu}-\mathrm{K} \alpha$ radiation was used to identify the phases of the coating, using the grazing incidence technique with an incident angle of $1^{\circ}$. The crystal structure and preferred orientation of the $\mathrm{CrN}$ films were characterized by XRD. The extent of the (111) preferred crystallographic orientation was quantified using a texture coefficient defined as $I(111) /[I(111)$ 
$+I(200)+I(220)]$, where $I$ refers to the integrated intensity of the corresponding Bragg peak. A field emission electron probe microanalyzer (FE-EPMA, JEOL, JXA-8500F, Tokyo, Japan) was used to analyze the chemical composition of the coatings. The residual stress of the coatings was evaluated using the substrate curvature method, which involved measuring the thickness of the coatings and the curvature of the Si wafer before and after deposition. Residual stress was calculated using Stoney's equation [36]. The mechanical properties of the $\mathrm{CrN} / \mathrm{CrAlSiN}$ multilayer coatings were analyzed on HSS substrates. Adhesion strength was measured using scratch tests with a Rockwell diamond stylus. The parameters of the scratch test were as follows: scratch speed was $2 \mathrm{~mm} / \mathrm{min}$, scratch length was $5 \mathrm{~mm}$, and load was 1-100 N. The critical loads of the coating were evaluated according to the exfoliation of the coating and were determined by an optical microscope after each scratch test. Each coating was scratched three times to avoid accidental errors. The hardness and Young's modulus of the coatings were measured using a nano-indentation instrument (TI-900, TriboIndenter, Hysitron, Minneapolis, MN, USA) with a Berkovich diamond indenter. The hardness and elastic modulus of each indent were determined using the Oliver and Pharr method [37]. The loading rate was $1000 \mu \mathrm{N} / \mathrm{s}$ and the maximum indentation depth was controlled to $100 \mathrm{~nm}$ to minimize the influence of the substrate on hardness measurements. Seven indents were measured to obtain the average hardness and elastic modulus values.

Table 2. Element concentration as a function of thickness in bi-layer CrAlSiN/CrN multilayer coatings.

\begin{tabular}{ccccccc}
\hline \multirow{2}{*}{$\begin{array}{c}\text { Rotation Speed } \\
(\mathbf{r p m})\end{array}$} & Thickness (nm) & \multicolumn{5}{c}{ Element Concentration (at.\%) } \\
\cline { 2 - 7 } & Bi-Layer & $\mathbf{C r}$ & $\mathbf{A l}$ & $\mathbf{N}$ & $\mathbf{S i}$ & $\mathbf{O}$ \\
\hline 1.5 & 12 & 51.8 & 30.1 & 12.6 & 5.1 & 0.5 \\
2 & 9.5 & 52.1 & 29.7 & 12.6 & 5.2 & 0.4 \\
3 & 6 & 52.1 & 29.5 & 13.1 & 5.0 & 0.5 \\
4 & 4 & 51.7 & 28.6 & 14.4 & 5.1 & 0.2 \\
5 & 3.2 & 50.5 & 29.6 & 14.1 & 5.5 & 0.6 \\
\hline
\end{tabular}

\section{Results and Discussion}

Figure 2 presents TEM images and SAED patterns of the CrN/CrAlSiN multilayer coatings fabricated using rotation rates of 1.5, 3, and $5 \mathrm{rpm}$. In the image, the lighter layers are CrAlSiN and the darker layers are $\mathrm{CrN}$. The strong contrast between the layers can be attributed to differences in the electron scattering factor of $\mathrm{Cr}$ and CrAlSi. The thickness of the bi-layer decreased from 12 to $3.2 \mathrm{~nm}$ when the rate of rotation was increased from 1.5 to $5 \mathrm{rpm}$, as shown in Table 2. This trend can be attributed to the sputter yield of the CrAlSi targets being higher than that of the Cr targets [30]. Increasing the rate of substrate rotation decreased the thickness of the CrAlSiN monolayer film by reducing the time in which the substrate remained within the range of the CrAISi targets. Increasing the rotation speed then decreased the thickness of the $\mathrm{CrN}$ monolayer film. SAED analysis revealed the presence of fine diffraction rings related to the (111), (200), and (220) planes in the $\mathrm{NaCl}$ structure, indicating the existence of only a single phase related to $\mathrm{Cr}(\mathrm{Al}) \mathrm{N}$ (i.e., no additional phases).

Table 2 lists the relative concentrations of elements in $\mathrm{CrN} / \mathrm{CrAlSiN}$ multilayer coatings with various bi-layer thicknesses. The atomic content remained consistent among all samples, regardless of thickness: $\mathrm{Cr}$ (51 at.\%), $\mathrm{Al}(30$ at. $\%), \mathrm{N}$ (13 at.\%), Si (5 at.\%), and $\mathrm{O}(<0.5$ at.\%). Note that under various bi-layer thicknesses, the concentration of $\mathrm{Cr}$ exceeded that of Al. Determining the Cr: $\mathrm{N}$ ratio in the overall structure was complicated by the presence of $\mathrm{Cr}$ in the $\mathrm{CrN}$ interlayer as well as $\mathrm{N}$ in the CrAlSiN multilayer. Finally, the sensitivity of the electron probe microanalyzer (EPMA) is somewhat limited in resolving complex structures (multilayer structures with the same elements distributed in multiple layers) [38]. As far as EPMA measurement technology is concerned, the large information depth of X-rays shows that a depth resolution of about $0.1-6 \mu \mathrm{m}$ could be determined [39]. 

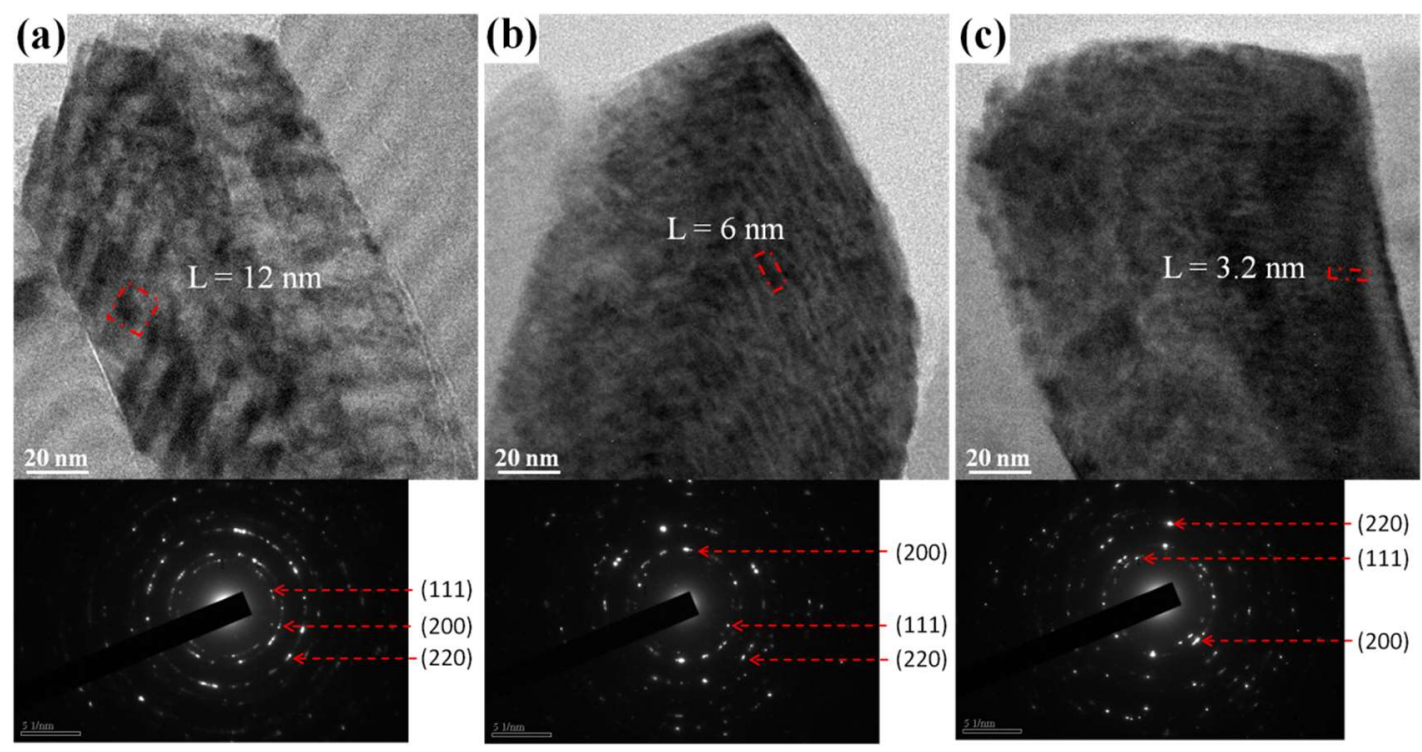

Figure 2. TEM micrographs and corresponding diffraction patterns of $\mathrm{CrN} / \mathrm{CrAlSiN}$ multilayer films fabricated using various rotation speeds: (a) 1.5; (b) 3; and (c) $5 \mathrm{rpm}$.

Figure 3 presents XRD patterns of $\mathrm{CrN} / \mathrm{CrAlSiN}$ multilayer coatings with bi-layers of various thicknesses. The diffraction peaks observed at $2 \theta=37.5^{\circ}, 43.6^{\circ}, 63.4^{\circ}$, and $76.1^{\circ}$, respectively, correspond to (111), (200), (220), and (310) planes in the face-centered cubic (FCC) structure of CrN based on JCPDS-ICDD No. 03-65-9001. These results are in good agreement with the SAED patterns. The intensity of the (111) peak clearly increased with a decrease in the thickness of the bi-layer from 12 to $3.2 \mathrm{~nm}$, which suggested that a thinner bi-layer restrains the phase growth of (200), (220), and (311) textured planes resulting in (111) preferential growth. The change in the intensity of the peaks was an indication of improved crystallinity and an increase in crystallite size. Specifically, decreasing the thickness of the bi-layer from 12 to $3.2 \mathrm{~nm}$ increased the crystallite size on the (111) plane from 11.6 to $19.7 \mathrm{~nm}$. This may be attributed to the nucleation of new grains on top of the old grains in the thinner samples [40]. The negative satellite peak $(m=-1)$ on the left side of the main Bragg diffraction (111) peak further confirmed the superlattice structure of the CrN/CrAlSiN multilayer coatings [41], as indicated in Figure 3. Decreases in the thickness of the bi-layer increased the space between the (111) peak and the satellite peak $(\mathrm{m}=-1)$.

Figure 4 presents cross-sectional (Figure 4a) and top-view (Figure 4b) SEM images of CrN/CrAlSiN multilayer coatings with bi-layers of various thicknesses. All of the coatings presented a dense crystal surface without macroscopic particles due to the high kinetic energy of the metal ions during HiPIMS deposition [42]. The cross-sectional SEM image in Figure 4a indicates the columnar crystal microstructure of the CrN/CrAlSiN films. Note that the thickness of the coating layer remained constant $(2870 \mathrm{~nm})$, even when the rotation rate increased from 1.5 to $5 \mathrm{rpm}$. It appears that the transfer interlayer (dark layer), which appeared in all of the coatings, can be attributed to an increase in the $\mathrm{N}_{2}$ flow from $18 \%$ (for $\mathrm{CrN}$ coating) to $48 \%$ (for CrN/CrAlSiN multilayer coating) during deposition. Decreasing the thickness of the bi-layer tended to reduce the size of the columnar crystals by limiting the time available for grain growth. The results of refined columnar structure can be attributed to the limited growth of the columnar structure, which was hindered by the decreasing bi-layer thickness of the coatings due to an insufficient deposition time to induce grain growth [43]. 


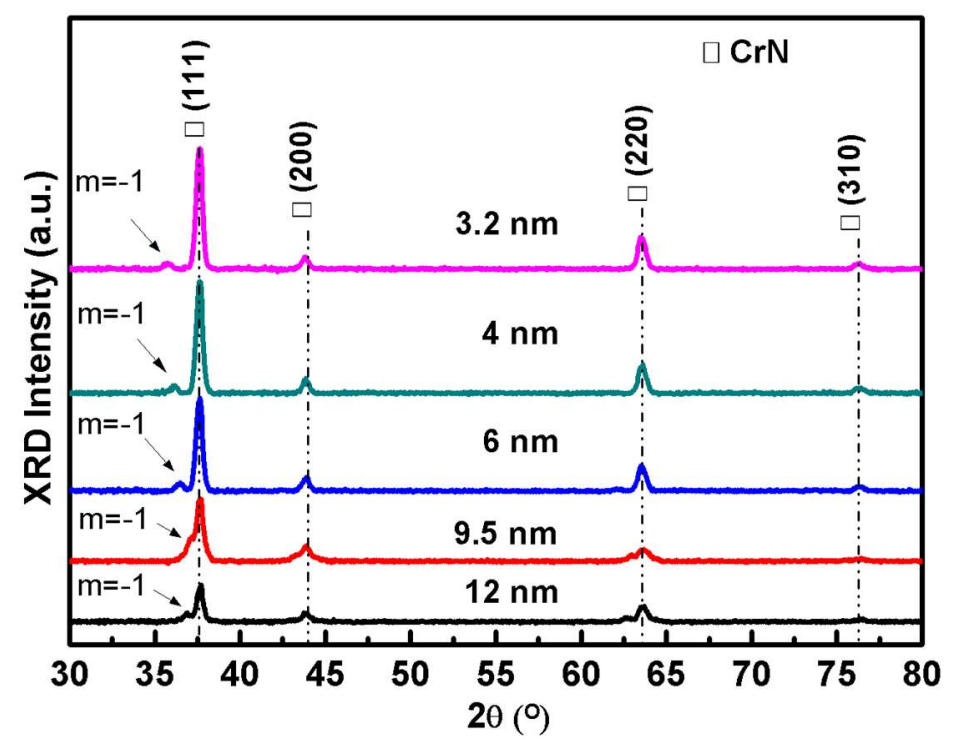

Figure 3. X-ray diffractometer (XRD) patterns obtained from $\mathrm{CrN} / \mathrm{CrAlSiN}$ multilayer coatings with bi-layers of various thicknesses: $12,9.5,6,4$, and $3.2 \mathrm{~nm}$.

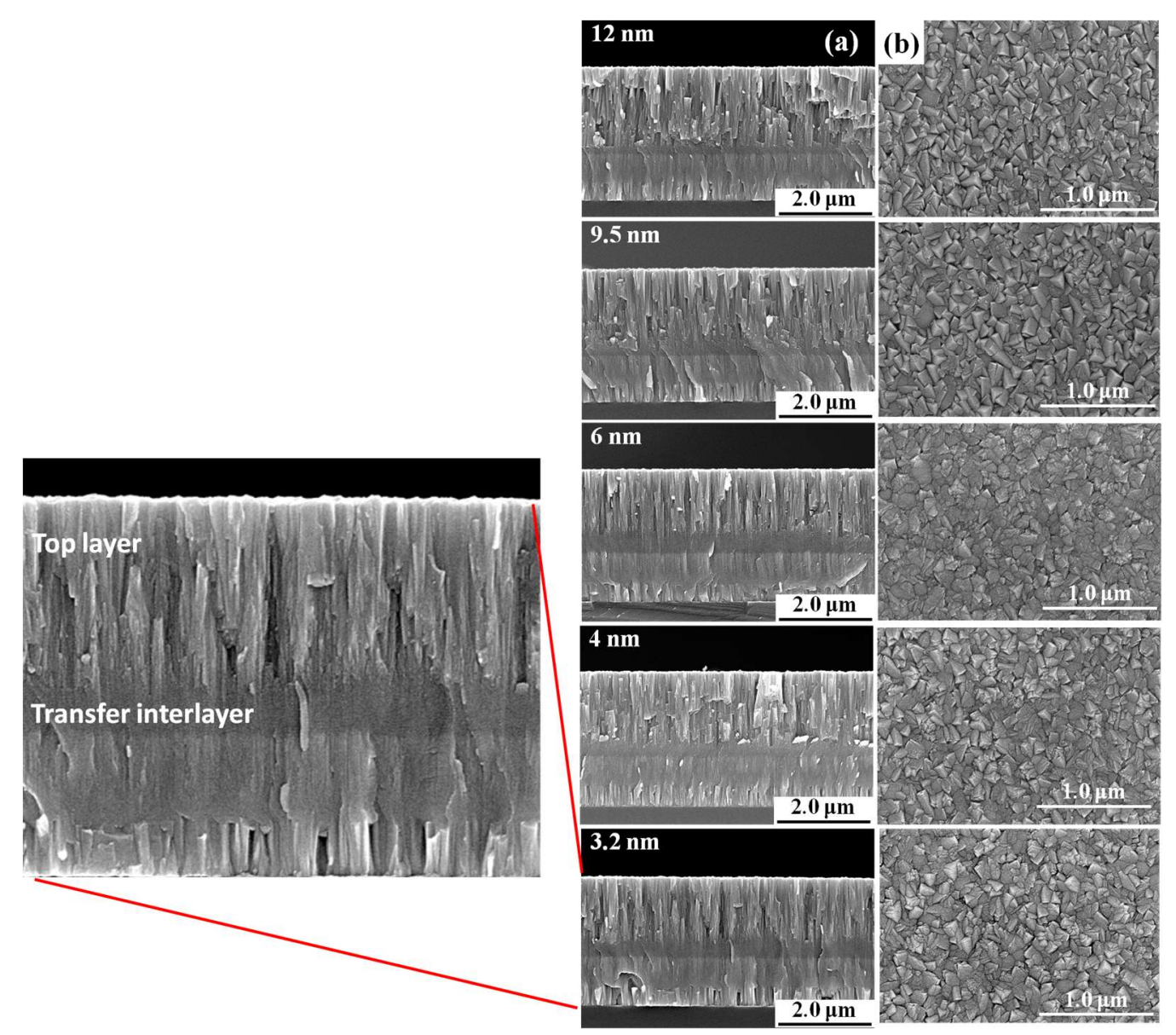

Figure 4. Cross-sectional (a) and top-view (b) SEM images of bi-layer coatings of various thicknesses.

Figure 5 presents the hardness and elastic modulus of $\mathrm{CrN} / \mathrm{CrAlSiN}$ multilayer coatings with bi-layers of various thicknesses. Decreasing the thickness of the bi-layer from 12 to $3.2 \mathrm{~nm}$ increased the hardness from 16.4 to $20.1 \mathrm{GPa}$. It also increased the elastic modulus from 291 to $336 \mathrm{GPa}$. Fu et al. [44] 
reported that multilayer structures minimize the intermixing of the component layers, which increases hardness. This implies that a narrow interface width can enhance the strength and hardness of the superlattice [45]. Araujo et al. [46] reported an increase in the hardness of $\mathrm{NbN} / \mathrm{CrN}$ films corresponding to a decrease in periodicity from 20 to $4 \mathrm{~nm}$ due to the effects of dislocation confinement across layer interfaces. Film hardness is related to the structure of the film, including preferred orientation, full width at half maximum (FWHM), and defect density. Researchers also reported that the nanohardness of TiN films is proportional to the (111) texture coefficient. In this study, the (111) texture coefficient was calculated as a function of the bi-layer thickness, as follows: $0.61(12 \mathrm{~nm})$, $0.70(9.5 \mathrm{~nm}), 0.72(6 \mathrm{~nm}), 0.73(4 \mathrm{~nm})$, and $0.74(3.2 \mathrm{~nm})$. Overall, bi-layer thickness was inversely proportional to the (111) texture coefficient and hardness. Zukerman et al. [47] reported that the higher hardness of many thin films can be attributed to high residual stress. Chang et al. [48] reported that the variation in hardness is evidently related to that of residual stress. In the current study, residual stress was calculated as a function of bi-layer thickness, as follows: $-0.5 \pm 0.3 \mathrm{GPa}(12 \mathrm{~nm}),-0.5 \pm 0.25 \mathrm{GPa}$ $(9.5 \mathrm{~nm}),-0.6 \pm 0.14 \mathrm{GPa}(6 \mathrm{~nm}),-0.6 \pm 0.18 \mathrm{GPa}(4 \mathrm{~nm})$, and $-0.6 \pm 0.22 \mathrm{GPa}(3.2 \mathrm{~nm})$. When the bi-layer thickness decreased from 12 to $3.2 \mathrm{~nm}$, the columnar structure with average width decreased from 86.3 to $78.3 \mathrm{~nm}$. Note that average width value of columnar structure is strongly related to film hardness. The width of columnar structure was estimated from TEM images (data not shown).

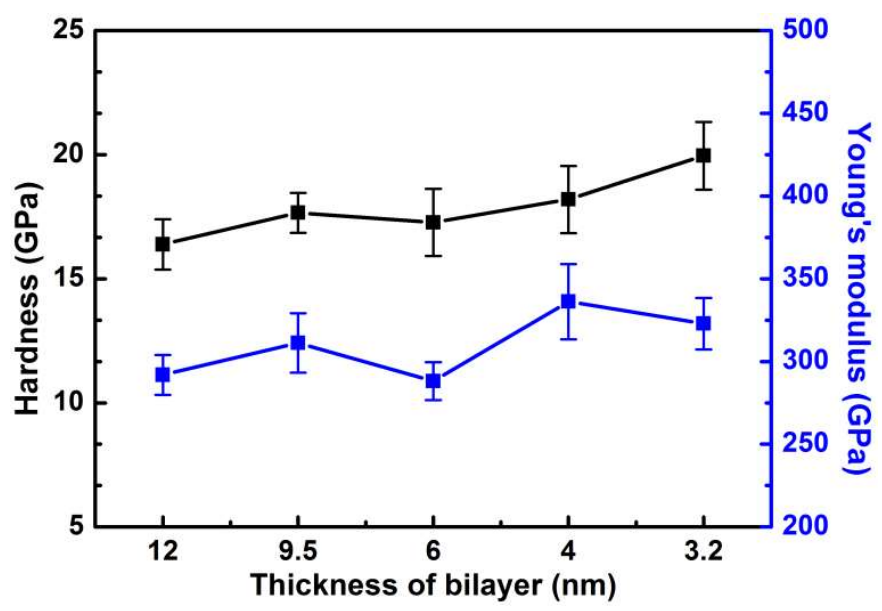

Figure 5. Hardness and Young's modulus values of CrN/CrAlSiN coatings with bi-layers of various thicknesses.

Substrate rotation also showed a significant effect on the strength of adhesion between the coating and substrate. Figures 6 and 7 present the adhesion strength of $\mathrm{CrN} / \mathrm{CrAlSiN}$ multilayer coatings with bi-layers of various thicknesses on HSS substrates, as measured using Rockwell $\mathrm{C}$ indentation (Future-Tech Corp., Kawasaki, Japan) and scratch tests. The aspect of the HRC indentations was compared with standard patterns. Rockwell tests were conducted according to ISO 26443 [49], classifying the strength from HF1 (high adhesive strength) up to HF6 (very low adhesive strength). In general, Lc1 is defined as the load required to yield the first crack inside and can be determined by studying scratch morphologies. All of the $\mathrm{CrN} / \mathrm{CrAlSiN}$ multilayer coatings qualified as Class 0 (ISO 26443), which is equivalent to HF1, and had a scratch test Lc1 value exceeding $50 \mathrm{~N}$. This excellent adhesion performance can be mainly to attributed the well-defined crystal structure at the coating-substrate interface, resulting from the effects of HiPIMS metal ion etching and the graded interlayer structure of the coating system [50,51]. For a hard coating, coating failure in the scratch test was mainly caused by interface defects between coating and substrate, plastic deformation and fracture within the coating [52]. The first crack process occurs in the bordering zones due to the defects between the films to substrate. By increasing the indentation load, the cracks spread to the periphery, outside the indentation track, wherein delamination began, as indicated by Lc1 point [53]. Note that 
decreasing the thickness of the bi-layer from 12 to $3.2 \mathrm{~nm}$ increased the Lc1 value from 56.1 to $76.9 \mathrm{~N}$ due to enhanced hardness. This provides more resistance to plastic deformation and provides the optimal $\Lambda$ for $\mathrm{CrN} / \mathrm{CrAlSiN}$ multilayer coatings.
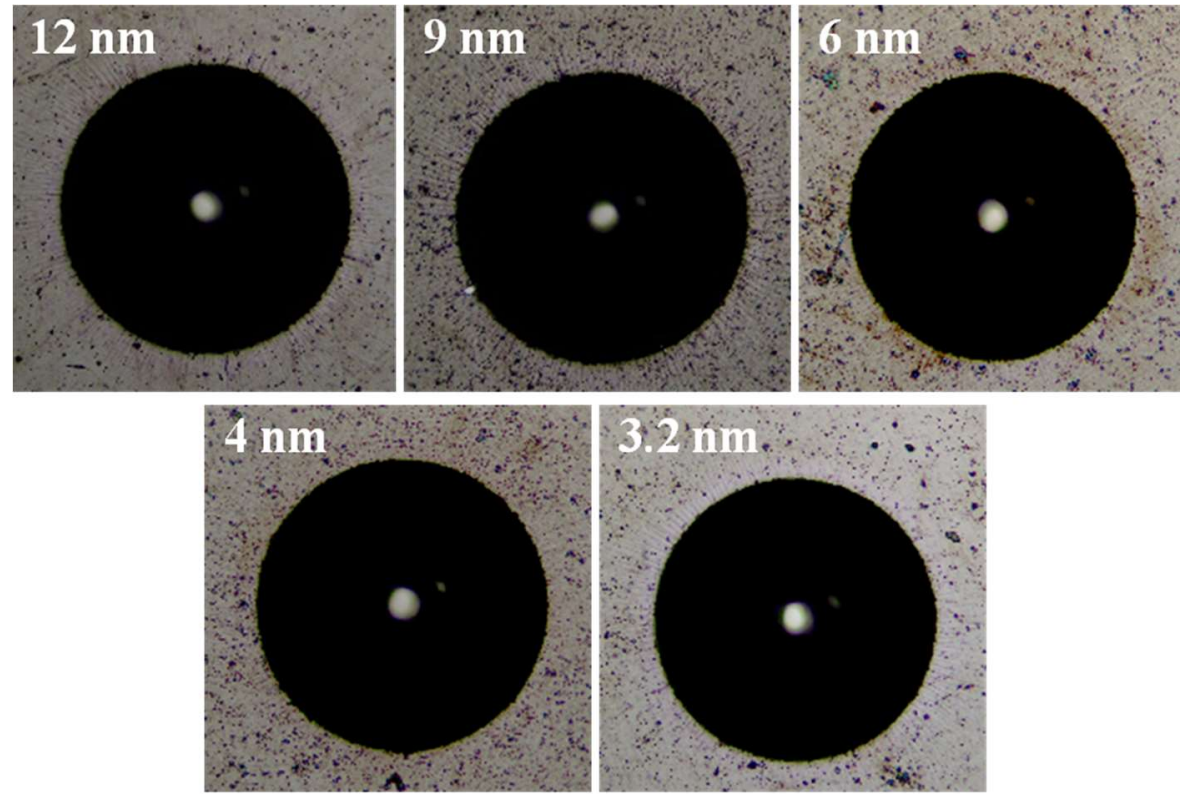

Figure 6. Rockwell indentations of $\mathrm{CrN} / \mathrm{CrAlSiN}$ multilayer coatings as a function of the bi-layer thickness.

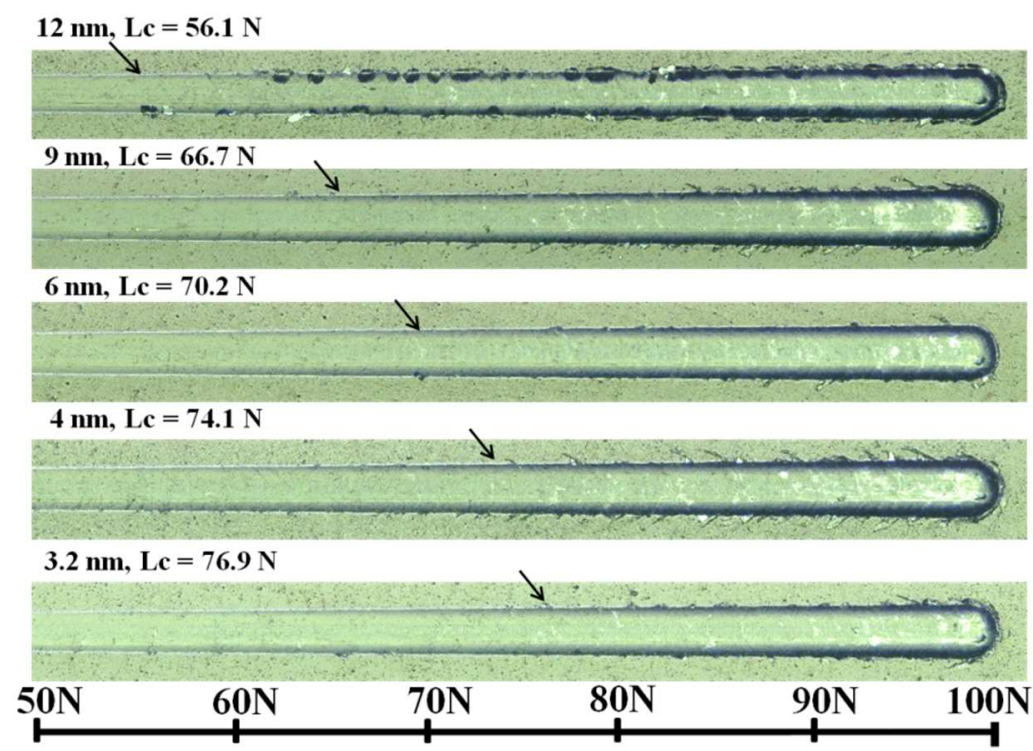

Figure 7. Scratch tracks of CrN/CrAlSiN multilayer coatings with bi-layers of various thicknesses.

Characterizing the microstructure of the multilayer and interlayer using SEM proved problematic; therefore, we performed TEM analysis to examine the influence of microstructure on adhesion performance. The cross-sectional TEM micrographs in Figure 8 show clear interfaces in the transfer layer and CrN/CrAlSiN multilayer structure. Region I formed under an $\mathrm{N}_{2}$ flow of $18 \%$ (CrN coating), whereas Region II formed under an $\mathrm{N}_{2}$ flow of $48 \%$ (multilayer coating) during the deposition process. Note that Region I in the TEM images is the same as the dark layer in the SEM images. Region II formed under a different sputtering yield of $\mathrm{Cr}$ and $\mathrm{CrAlSi}$ targets and different substrate rotation speed. Figure 8a presents the columnar crystal structure in Region II, which grew along the transfer layer 
under the same rotation speed used in the deposition of Region I (1.5 rpm). The red dash-dotted lines in the Figure 8a represent the single crystal column. The majority of columns extend through the whole coating: starting from the nucleation zone on the substrate. Figure $8 b, c$ show the smaller columnar crystals that formed in Region II under higher substrate rotation speeds. The smaller columnar crystals improving adhesion performance can be explained as follows: (1) The layer of columnar crystals in Region II grew along the bottom layer of Region I, such that stress was focused on a specific narrow point (single crystal column), as indicated by the region between the red dash-dotted lines in Figure 8a. (2) Increasing the rotation speed of the top layers reduced the size of the columnar crystal in Region II, thereby allowing the stress to be dispersed (as shown in schematic diagram of Figure 8, as indicated by the regions between the red dash-dotted lines in Figure 8b,c; and (3) increasing the number of the interlayer interfaces (hence decreasing the bi-layer period), additional barriers appear hindering the column's glide [54].

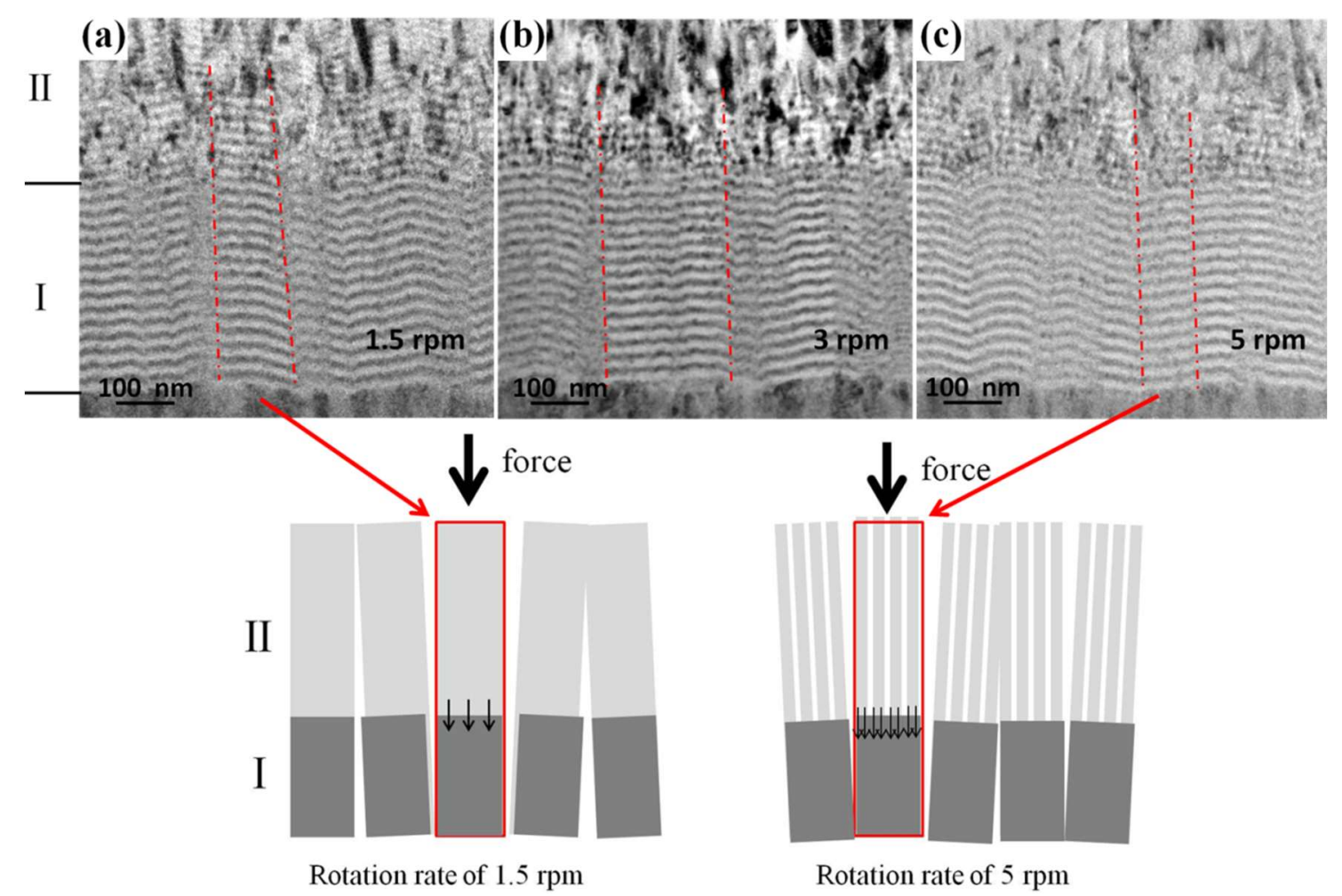

Figure 8. TEM micrographs of interlayer films beneath $\mathrm{CrN} / \mathrm{CrAlSiN}$ multilayer coatings with bi-layers of various thicknesses: (a) 12; (b) 6; and (c) $3.2 \mathrm{~nm}$.

\section{Conclusions}

In this study, we investigated the influence of substrate rotation speed on the microstructure and mechanical properties of $\mathrm{CrN} / \mathrm{CrAlSiN}$ multilayer coatings fabricated using high-power impulse magnetron sputtering on silicon and high-speed steel substrates. Thinner $\mathrm{CrN} / \mathrm{CrAlSiN}$ bi-layer coatings presented a higher (111) texture coefficient, higher residual stress, and refined grain structure, which increased the hardness to $20.1 \mathrm{GPa}$ and elastic modulus to $336 \mathrm{GPa}$. TEM analysis revealed that the columnar crystal structure of the thinner bi-layers was more refined, which increased the hardness as well as the adhesion strength to $76.9 \mathrm{~N}$. The high adhesion strength observed in this study can be attributed to stress that was dispersed by the refined columnar structure on the transfer layer. Taken together, these results indicated that the mechanical properties and adhesion strength of the coatings can both be enhanced simply by increasing the substrate rotation speed during deposition. 
Author Contributions: Methodology, C.-H.H.; investigation, C.-H.H. and C.-Y.L.; resources, F.-C.Y.; data curation, C.-Y.L.; writing-original draft, J.-F.T.; writing-review \& editing, J.-F.T. and C.-L.C.; project administration, C.-L.C.; supervision, C.-L.C. All authors have read and agreed to the published version of the manuscript.

Funding: This research was funded by the Ministry of Science and Technology, Taiwan, R.O.C, grant number [MOST 107-2622-E-131-001-CC2], [MOST 107-2218-E-131-001], [MOST 107-2221-E-131-003] and [MOST 108-2221-E-131-013].

Acknowledgments: The authors gratefully acknowledge the use of the FE-EPMA (JXA-iHP200F) apparatus at the Instrument Center of National Tsing Hua University. The authors gratefully acknowledge the use of HR-SEM (Hitachi SU8000) equipment belonging to the Instrument Center of National Cheng Kung University.

Conflicts of Interest: The authors declare no conflict of interest.

\section{References}

1. Chang, C.-L.; Yang, F.-C. Synthesis and characteristics of nc-WC/a-C:H thin films deposited via a reactive HIPIMS process using optical emission spectrometry feedback control. Surf. Coat. Technol. 2018, 350, 1120-1127. [CrossRef]

2. Kong, Y.; Tian, X.; Gong, C.; Chu, P.K. Reprint of "Enhancement of toughness and wear resistance by $\mathrm{CrN} / \mathrm{CrCN}$ multilayered coatings for wood processing". Surf. Coat. Technol. 2018, 355, 318-327. [CrossRef]

3. Kabir, M.S.; Munroe, P.; Zhou, Z.; Xie, Z. Structureand mechanical properties of graded Cr/CrN/CrTiN coatings synthesized by close field unbalanced magnetron sputtering. Surf. Coat. Technol. 2017, 309, 779-789. [CrossRef]

4. Kong, Y.; Tian, X.; Gong, C.; Chu, P.K. Enhancement of toughness and wear resistance by $\mathrm{CrN} / \mathrm{CrCN}$ multilayered coatings for wood processing. Surf. Coat. Technol. 2018, 344, 204-213. [CrossRef]

5. Rabadzhiyska, S.; Kolaklieva, L.; Chitanov, V.; Cholakova, T.; Kakanakov, R.; Dimcheva, N.; Balashev, K. Mechanical, wear and corrosion behavior of $\mathrm{CrN} / \mathrm{TiN}$ multilayer coatings deposited by low temperature unbalanced magnetron sputtering for biomedical applications. Mater. Today-Proc. 2018, 5, 16012-16021. [CrossRef]

6. Chen, X.; Gao, H.; Bai, Y.; Yang, H. Thermal failure mechanism of multilayer brittle TiN/CrAlN films. Ceram. Int. 2018, 44, 8138-8144. [CrossRef]

7. Cheng, C.-H.; Lee, J.-W.; Ho, L.-W.; Chen, H.-W.; Chan, Y.-C.; Duh, J.-G. Microstructure and mechanical property evaluation of pulsed DC magnetron sputtered $\mathrm{Cr}-\mathrm{B}$ and $\mathrm{Cr}-\mathrm{B}-\mathrm{N}$ films. Surf. Coat. Technol. 2011, 206, 1711-1719. [CrossRef]

8. Hu, C.; Xu, Y.X.; Chen, L.; Pei, F.; Du, Y. Mechanical properties, thermal stability and oxidation resistance of Ta-doped CrAlN coatings. Surf. Coat. Technol. 2019, 368, 25-32. [CrossRef]

9. Polychronopoulou, K.; Baker, M.; Rebholz, C.; Neidhardt, J.; O'Sullivan, M.; Reiter, A.; Kanakis, K.; Leyland, A.; Matthews, A.; Mitterer, C. The nanostructure, wear and corrosion performance of arc-evaporated $\mathrm{CrB}_{x} \mathrm{~N}_{y}$ nanocomposite coatings. Surf. Coat. Technol. 2009, 204, 246-255. [CrossRef]

10. Li, B.-S.; Wang, T.-G.; Ding, J.; Cai, Y.; Shi, J.; Zhang, X. Influence of N2/Ar flow ratio on microstructure and properties of the $\mathrm{AlCrSiN}$ coatings deposited by high-power impulse magnetron sputtering. Coatings 2018, 8, 3. [CrossRef]

11. Zhang, S.; Wang, L.; Wang, Q.; Li, M. A superhard CrAlSiN superlattice coating deposited by multi-arc ion plating: I. Microstructure and mechanical properties. Surf. Coat. Technol. 2013, 214, 160-167. [CrossRef]

12. Chang, C.-C.; Chen, H.-W.; Lee, J.-W.; Duh, J.-G. Influence of Si contents on tribological characteristics of CrAlSiN nanocomposite coatings. Thin Solid Film. 2015, 584, 46-51. [CrossRef]

13. Morshed, M.; McNamara, B.; Cameron, D.; Hashmi, M. Effect of surface treatment on the adhesion of DLC film on 316L stainless steel. Surf. Coat. Technol. 2003, 163, 541-545. [CrossRef]

14. Ehiasarian, A.; Wen, J.; Petrov, I. Interface microstructure engineering by high power impulse magnetron sputtering for the enhancement of adhesion. J. Appl. Phys. 2007, 101, 054301. [CrossRef]

15. Bakoglidis, K.D.; Schmidt, S.; Greczynski, G.; Hultman, L. Improved adhesion of carbon nitride coatings on steel substrates using metal HiPIMS pretreatments. Surf. Coat. Technol. 2016, 302, 454-462. [CrossRef]

16. Lattemann, M.; Ehiasarian, A.; Bohlmark, J.; Persson, P.; Helmersson, U. Investigation of high power impulse magnetron sputtering pretreated interfaces for adhesion enhancement of hard coatings on steel. Surf. Coat. Technol. 2006, 200, 6495-6499. [CrossRef] 
17. Schönjahn, C.; Ehiasarian, A.; Lewis, D.; New, R.; Münz, W.-D.; Twesten, R.; Petrov, I. Optimization of in situ substrate surface treatment in a cathodic arc plasma: A study by TEM and plasma diagnostics. J. Vac. Sci. Technol. A 2001, 19, 1415-1420. [CrossRef]

18. Macák, K.; Kouznetsov, V.; Schneider, J.; Helmersson, U.; Petrov, I. Ionized sputter deposition using an extremely high plasma density pulsed magnetron discharge. J. Vac. Sci. Technol. A 2000, 18, 1533-1537. [CrossRef]

19. Purandare, Y.; Ehiasarian, A.; Santana, A.; Hovsepian, P. ZrN coatings deposited by high power impulse magnetron sputtering and cathodic arc techniques. J. Vac. Sci. Technol. A 2014, 32, 031507. [CrossRef]

20. He, N.; Li, H.; Ji, L.; Liu, X.; Zhou, H.; Chen, J. High temperature tribological properties of TiAlSiN coatings produced by hybrid PVD technology. Tribol. Int. 2016, 98, 133-143. [CrossRef]

21. Baptista, A.; Silva, F.; Porteiro, J.; Míguez, J.; Pinto, G.; Fernandes, L. On the physical vapour deposition (PVD): Evolution of magnetron sputtering processes for industrial applications. Procedia Manuf. 2018, 17, 746-757. [CrossRef]

22. Bräuer, G.; Szyszka, B.; Vergöhl, M.; Bandorf, R. Magnetron sputtering-Milestones of 30 years. Vacuum 2010, 84, 1354-1359. [CrossRef]

23. Hashmi, S. Comprehensive Materials Processing; Newnes: Amsterdam, The Netherlands, 2014.

24. Samuelsson, M.; Lundin, D.; Jensen, J.; Raadu, M.A.; Gudmundsson, J.T.; Helmersson, U. On the film density using high power impulse magnetron sputtering. Surf. Coat. Technol. 2010, 205, 591-596. [CrossRef]

25. Paulitsch, J.; Schenkel, M.; Zufraß, T.; Mayrhofer, P.H.; Münz, W.-D. Structure and properties of high power impulse magnetron sputtering and DC magnetron sputtering $\mathrm{CrN}$ and TiN films deposited in an industrial scale unit. Thin Solid Film. 2010, 518, 5558-5564. [CrossRef]

26. Shinn, M.; Hultman, L.; Barnett, S. Growth, structure, and microhardness of epitaxial TiN/NbN superlattices. J. Mater. Res. 1992, 7, 901-911. [CrossRef]

27. Guimaraes, M.C.R.; de Castilho, B.C.N.M.; Nossa, T.d.; Avila, P.R.T.; Cucatti, S.; Alvarez, F.; Garcia, J.L.; Pinto, H.C. On the effect of substrate oscillation on $\mathrm{CrN}$ coatings deposited by HiPIMS and dcMS. Surf. Coat. Technol. 2018, 340, 112-120. [CrossRef]

28. Gu, X.; Zhang, Z.; Bartosik, M.; Mayrhofer, P.H.; Duan, H. Dislocation densities and alternating strain fields in CrN/AlN nanolayers. Thin Solid Film. 2017, 638, 189-200. [CrossRef]

29. Cabrera, G.; Caicedo, J.; Amaya, C.; Yate, L.; Saldaña, J.M.; Prieto, P. Enhancement of mechanical and tribological properties in AISI D3 steel substrates by using a non-isostructural CrN/AlN multilayer coating. Mate. Chem. Phys. 2011, 125, 576-586. [CrossRef]

30. Liu, H.; Yang, F.-C.; Tsai, Y.-J.; Wang, X.; Li, W.; Chang, C.-L. Effect of modulation structure on the microstructural and mechanical properties of TiAlSiN/CrN thin films prepared by high power impulse magnetron sputtering. Surf. Coat. Technol. 2019, 358, 577-585. [CrossRef]

31. Chan, Y.-C.; Chen, H.-W.; Tsai, Y.-Z.; Duh, J.-G.; Lee, J.-W. Texture, microstructure and anti-wear characteristics in isostructural CrAlSiN/W $2 \mathrm{~N}$ multilayer coatings. Thin Solid Film. 2013, 544, 265-269. [CrossRef]

32. Illana, A.; Almandoz, E.; Fuentes, G.G.; Pérez, F.J.; Mato, S. Comparative study of CrAlSiN monolayer and $\mathrm{CrN} / \mathrm{AlSiN}$ superlattice multilayer coatings: Behavior at high temperature in steam atmosphere. J. Alloys Compd. 2019, 778, 652-661. [CrossRef]

33. Ou, Y.; Lin, J.; Tong, S.; Sproul, W.; Lei, M. Structure, adhesion and corrosion behavior of CrN/TiN superlattice coatings deposited by the combined deep oscillation magnetron sputtering and pulsed dc magnetron sputtering. Surf. Coat. Technol. 2016, 293, 21-27. [CrossRef]

34. Martınez, E.; Romero, J.; Lousa, A.; Esteve, J. Wear behavior of nanometric CrN/Cr multilayers. Surf. Coat. Technol. 2003, 163, 571-577. [CrossRef]

35. Liu, H.; Tang, J.-F.; Wang, X.; Li, W.; Chang, C.-L. Effects of nitrogen-argon flow ratio on the microstructural and mechanical properties of TiAlSiN/CrN multilayer coatings prepared using high power impulse magnetron sputtering. J. Vac. Sci. Technol. A 2019, 37, 051501. [CrossRef]

36. Wang, H.; Deng, H.; Chiang, S.; Su, Y.; Chiang, K. Development of a process modeling for residual stress assessment of multilayer thin film structure. Thin Solid Film. 2015, 584, 146-153. [CrossRef]

37. Oliver, W.C.; Pharr, G.M. An improved technique for determining hardness and elastic modulus using load and displacement sensing indentation experiments. J. Mater. Res. 1992, 7, 1564-1583. [CrossRef]

38. Richter, S.; Karduck, P. EPMA sputter depth profiling of an InGaAs-InP heterostructure. Fresenius J. Anal. Chem. 1999, 365, 221-226. [CrossRef] 
39. Willich, P.; Bethke, R. Performance and limitations of electron probe microanalysis applied to the characterization of coatings and layered structures. Fresenius J. Anal. Chem. 1995, 353, 389-392. [CrossRef]

40. Shree, B.L.; Priya, S.S.; Ranjani, P.T.; Karthick, P.; Jeyadheepan, K.; Sridharan, M. Influence of CdTe Thickness on the properties of vacuum evaporated CdSe/CdTe bilayer. Mater. Today-Proc. 2016, 3, 1494-1501. [CrossRef]

41. Lin, J.; Moore, J.J.; Mishra, B.; Pinkas, M.; Zhang, X.; Sproul, W.D. CrN/AlN superlattice coatings synthesized by pulsed closed field unbalanced magnetron sputtering with different $\mathrm{CrN}$ layer thicknesses. Thin Solid Film. 2009, 517, 5798-5804. [CrossRef]

42. Oliveira, J.C.; Ferreira, F.; Anders, A.; Cavaleiro, A. Reduced atomic shadowing in HiPIMS: Role of the thermalized metal ions. Appl. Surf. Sci. 2018, 433, 934-944. [CrossRef]

43. Chang, C.-L.; Jao, J.-Y.; Ho, W.-Y.; Wang, D.-Y. Influence of bi-layer period thickness on the residual stress, mechanical and tribological properties of nanolayered TiAlN/CrN multi-layer coatings. Vacuum 2007, 81, 604-609. [CrossRef]

44. Zhou, S.; Yan, S.; Han, B.; Yang, B.; Lin, B.; Zhang, Z.; Ai, Z.; Pelenovich, V.; Fu, D. Influence of modulation period and modulation ratio on structure and mechanical properties of TiBN/CrN coatings deposited by multi-arc ion plating. Appl. Surf. Sci. 2015, 351, 1116-1121. [CrossRef]

45. Chu, X.; Barnett, S.A. Model of superlattice yield stress and hardness enhancements. J. Appl. Phys. 1995, 77, 4403-4411. [CrossRef]

46. Araujo, J.A.; Araujo, G.M.; Souza, R.M.; Tschiptschin, A.P. Effect of periodicity on hardness and scratch resistance of $\mathrm{CrN} / \mathrm{NbN}$ nanoscale multilayer coating deposited by cathodic arc technique. Wear 2015, 330, 469-477. [CrossRef]

47. Zukerman, I.; Raveh, A.; Shneor, Y.; Shneck, R.; Klemberg-Saphieha, J.; Martinu, L. Internal stress in TiAlBN at high temperatures. Surf. Coat. Technol. 2007, 201, 6161-6166. [CrossRef]

48. Chang, L.-C.; Zheng, Y.-Z.; Chen, Y.-I. Mechanical properties of Zr-Si-N films fabricated through HiPIMS/RFMS co-sputtering. Coatings 2018, 8, 263. [CrossRef]

49. ISO 26443-Fine ceramics (Advanced Ceramics, Advanced Technical Ceramics)—Rockwell Indentation Test for Evaluation of Adhesion of Ceramic Coating; International Organization for Standardization: Geneva, Switzerland, 2008.

50. Ma, D.; Harvey, T.; Wellman, R.; Ehiasarian, A.; Hovsepian, P.E.; Sugumaran, A.; Purandare, Y.; Wood, R. Cavitation erosion performance of CrAlYN/CrN nanoscale multilayer coatings deposited on Ti6Al4V by HIPIMS. J. Alloys Compd. 2019, 788, 719-728. [CrossRef]

51. Spies, H.-J.; Larisch, B.; Höck, K.; Broszeit, E.; Schröder, H.-J. Adhesion and wear resistance of nitrided and TiN coated low alloy steels. Surf. Coat. Technol. 1995, 74, 178-182. [CrossRef]

52. Zhang, X.; Tian, X.-B.; Zhao, Z.-W.; Gao, J.-B.; Zhou, Y.-W.; Gao, P.; Guo, Y.-Y.; Lv, Z. Evaluation of the adhesion and failure mechanism of the hard CrN coatings on different substrates. Surf. Coat. Technol. 2019, 364, 135-143. [CrossRef]

53. Quazi, M.M.; Ishak, M.; Arslan, A.; Bashir, M.N.; Ali, I. Scratch adhesion and wear failure characteristics of PVD multilayer CrTi/CrTiN thin film ceramic coating deposited on AA7075-T6 aerospace alloy. J. Adhes. Sci. Technol. 2018, 32, 625-641. [CrossRef]

54. Azizpour, A.; Hahn, R.; Klimashin, F.F.; Wojcik, T.; Poursaeidi, E.; Mayrhofer, H.P. Mayrhofer, Deformation and cracking mechanism in CrN/TiN multilayer coatings. Coatings 2019, 9, 363. [CrossRef]

(C) 2020 by the authors. Licensee MDPI, Basel, Switzerland. This article is an open access article distributed under the terms and conditions of the Creative Commons Attribution (CC BY) license (http://creativecommons.org/licenses/by/4.0/). 